\title{
JOGOS EDUCATIVOS EM TVDi: A GAMEFICAÇÃO DO GINGA
}

\author{
Lucas Silveira de Azevedo ${ }^{1}$, Fabio Cardoso ${ }^{2}$ \\ 1 Supervisor de Arte - TV Unesp; Doutorando PPG Design - Unesp, Bauru, Brasil, lucas@tvu.unesp.br \\ 2 Programador - TV Unesp; Mestre PPGTVD - Unesp, Bauru, Brasil, fabiocardoso@tvu.unesp.br
}

\begin{abstract}
Resumo: Toda tentativa de explorar novas formas de utilização da interatividade em televisão digital cria expectativas relacionadas aos seus resultados, principalmente quando se trata de processos educativos para o público infantil. Este artigo apresenta um estudo teórico-prático desenvolvido pela TV Unesp que demonstra a possibilidade de apropriação dos elementos do design de jogos em contextos não jogáveis. Oriunda de uma das linhas de pesquisa desenvolvidas na emissora, a série Apolônio e Azulão é constituída por doze episódios, cada um com dois momentos interativos gameficados que acompanham o conteúdo e oferecem possibilidades de explorar a interatividade no processo de compreensão do conteúdo por meio de jogos desenvolvidos em Ginga, evidenciando a viabilidade de integração dos jogos digitais à narrativa audiovisual educativa.
\end{abstract}

Palavras chave: Jogos Educativos, Televisão Digital, Interatividade, Gameficação, Ginga.

\section{INTRODUÇÃO}

A televisão é uma das mídias mais populares e importantes do Brasil, presente em 97,2\% dos domicílios no país [4], e permanece como relevante fonte de informação e entretenimento a brasileiros de diferentes níveis educacionais, idades e classes sociais, sendo um catalisador de relações sociais, culturais e econômicas.

$\mathrm{Na}$ década de 70 a televisão passou a ser utilizada com fins educacionais, além de entretenimento e informação, e de lá pra cá, ocorreram muitos avanços tecnológicos e de linguagens que modificaram drasticamente as formas de pensar, produzir e consumir este meio. O advento da Televisão Digital Interativa (TVDi) trouxe, entre outros avanços, a possibilidade de os telespectadores interagirem com o conteúdo audiovisual num ambiente hipermidiático, o que representa maior potencial de utilização da mídia para democratização da informação e conhecimento.

Além da televisão, os jogos digitais representam outra potencial ferramenta para utilização na educação, por conta de seu ambiente atraente e interativo que captura a atenção do jogador ao oferecer desafios que exigem níveis crescentes de destreza e habilidades [6]. Ao acrescentar os desafios dos jogos à narrativa audiovisual educativa, com objetivos de aprendizagem definidos e diretamente relacionado com o conteúdo veiculado, as práticas educacionais informais se tornam atrativas e inovadoras, onde o telespectador tem a chance de aprender de forma mais ativa, dinâmica e motivadora.

Por se apropriar de elementos do design de jogos em contextos não jogáveis, esta união entre o conteúdo televiso educativo e jogo digital se enquadra no conceito de gameficação, ou seja, a utilização de elementos de jogos para outros propósitos além de seus usos esperados em jogos de entretenimento [3].

Nesse contexto, o artigo apresenta um programa de televisão infantil interativo com conteúdo educativo e seriado desenvolvido pela Televisão Universitária Unesp (TV Unesp). A série Apolônio \& Azulão, por meio de seus dois personagens, aborda variados assuntos e situações cotidianas que englobam ciência, curiosidades e práticas sociais. Foram desenvolvidos doze episódios, cada um com dois momentos interativos que acompanham o conteúdo e oferecem possibilidades de explorar as potencialidades da interatividade no processo de assimilação do conteúdo por meio de jogos digitais educativos desenvolvidos em Ginga.

Com a finalidade de aprimorar o debate e fomentar as pesquisas relacionadas ao desenvolvimento de aplicações em Ginga para TVDi, o artigo foi desenvolvido em dois aspectos que se complementam: primeiro, a fundamentação teórica, baseada em pesquisas à literatura de diferentes áreas do conhecimento, segundo a experiência decorrente da vivência profissional como participantes do processo produtivo da série Apolônio \& Azulão.

O produto aqui apresentado ilustra os avanços na forma de encarar a utilização da interatividade em televisão digital, aliando jogos digitais à narrativa televisiva.

\section{2. É PRECISO "MUITA GINGA"}

O middleware Ginga, camada de software que executa as aplicações interativas no televisor, é uma das principais apostas do Governo Federal quanto ao Sistema Brasileiro de Televisão Digital - Terrestre (SBTVD-T). Pelo menos é o que aponta o fato de o Governo, após meses de negociação com entidades, ter definido por meio da Portaria Interministerial $n^{0} 140$, de 23 de fevereiro de 2012, a obrigatoriedade do Ginga ser embarcado em aparelhos fabricados a partir de 2013, respeitando um cronograma específico que resultou em $90 \%$ dos equipamentos produzidos com o middleware em 2014. O sinal de cobertura segue em plena expansão, cerca de $50 \%$ da população nacional recebe o sinal de TV Digital, e o desligamento do sinal 
analógico - switch-off - está programado para iniciar em abril de 2016 e terminar em novembro de 2018.

Contudo, a interatividade por meio da televisão digital, em Ginga, segue sendo pouco utilizada, talvez pelo crescimento no uso de dispositivos de segunda tela e também pela pouca oferta de aplicações interessantes, motivada pela falta de interesse comercial de fabricantes e produtores de conteúdo. Outros fatores preponderantes na pouca oferta das aplicações são as limitações de hardware e software.

Deixando de lado as limitações e as motivações dos envolvidos, observa-se que as aplicações disponibilizadas atualmente pelas emissoras apresentam pouca inovação referente à integração com o conteúdo audiovisual, limitando-se muitas vezes a apresentar a sinopse da atração e/ou capítulo, descrições dos personagens e ficha técnica, sem qualquer relação direta com a narrativa expressa pelo programa. Assim, despertam pouco ou quase nenhum interesse dos telespectadores.

Nesse sentido, a TV Unesp - emissora pública, cultural e educativa sediada na cidade de Bauru em São Paulo, e que tem como um de seus objetivos ser um centro de pesquisas nas áreas de comunicação, tecnologia, design e educação - busca impulsionar a progressão do SBTVD-T por meio de pesquisas e desenvolvimento sistemático de aplicações interativas em Ginga. As pesquisas, que aliam produção de conteúdo e tecnologia, estão em consonância com os novos sistemas produtivos e de circulação em televisão digital, colaborando com as definições das políticas públicas face à configuração dos fluxos comunicacionais no contexto da globalização, com as formas de apropriação sociocultural dos dispositivos tecnológicos diante das novas demandas, e às formas expressivas que articulam as linguagens dos diferentes meios voltada à comunicação em plataforma convergente.

O produto relatado neste artigo é oriundo de uma das linhas de pesquisa desenvolvidas na emissora, e diz respeito à integração de jogos digitais na narrativa audiovisual educativa, com objetivo de explorar novas formas de utilização da interatividade em televisão digital.

\section{JOGOS EM CONTEXTOS NÃO JOGÁVEIS}

Durante muito tempo a visão que se teve dos jogos digitais era a de uma atividade de lazer sem muitas preocupações em educar, hoje são inseridos na vida das crianças cada vez mais cedo também como ferramenta de estímulo à educação. Se antes a porta de entrada eram os videogames, atualmente, além destes dispositivos, estão presentes no cotidiano das crianças computadores, smartphones e tablets.

Visto que são interessantes, desafiadores e fazem superar limitações e obstáculos, os jogos digitais são muito utilizados por crianças como forma de entretenimento $e$ aprendizagem. $O$ ato de jogar proporciona à criança fácil assimilação daquilo que lhe é ensinado, estimulando inteligências ao permitir um envolvimento significativo com a tarefa realizada num ambiente lúdico.

Os jogos digitais, quando preparados para 0 contexto educacional, podem receber diferentes nomenclaturas. Normalmente são chamados de jogos educacionais ou educativos, jogos de aprendizagem ou jogos sérios (serious games) [6], como os simuladores eletrônicos utilizados no treinamento de condutores pelas auto-escolas, por exemplo.

A distinção entre jogos de entretenimento e gameficação ocorre pela aplicação de jogos a contextos que não sejam jogos de fato [5], como o conteúdo de um programa televisivo. Os elementos e características da obra audiovisual são utilizados no jogo, sendo que este último deve complementar o primeiro em termos de objetivos e experiência dos telespectadores, numa comunicação transmidiática.

Gameficar as experiências interativas nos produtos educativos infantis de televisão constitui em atribuir pontuações, estimular a meritocracia por meio de recompensas e proporcionar feedbacks instantâneos, com o objetivo de mudar comportamentos e contribuir para a absorção do conteúdo educativo apresentado pelo programa, além de integrar o uso de regras que podem motivar a criança na realização de tarefas cotidianas.

Os jogos digitais podem ser ferramentas eficientes no processo educacional informal, pois diverte enquanto motiva, facilita o aprendizado e aumenta a capacidade de retenção do que foi ensinado, exercitando as funções mentais, intelectuais, emocionais e físicas do jogador. Além de facilitar a memorização do conteúdo, os jogos podem estimular capacidades sensoriais, como a visão, audição e tato [1]. Nos jogos aplicados ao contexto televisivo, o sentido mais explorado é o da visão, enquanto a audição é empregada para aumentar a emoção com uso de sons coadjuvantes à ação. $O$ tato é explorado no manuseio do controle remoto, artefato que condiciona a interação com a interface televisiva por meio dos quatro botões coloridos - vermelho, verde, amarelo e azul - além das setas direcionais e botão "OK ou Enter". Estas são constatações preliminares a respeito da série Apolônio \& Azulão e testes de usabilidade e recepção de conteúdo trarão, quando aplicados, dados mais confiáveis a respeito dos estímulos das capacidades sensoriais e cognitivas.

\section{APOLÔNIO \& AZULÃO}

Enquanto emissora universitária, pertencente a uma instituição de ensino e pesquisa, a TV Unesp se coloca como um centro de investigação e experimentação em diferentes áreas do conhecimento com foco no aprimoramento científico capaz de apontar caminhos para a comunicação na sociedade da informação.

Ao considerar a carência, logo a demanda, por programas educativos infantis no interior paulista, a emissora observou a pertinência de desenvolver um programa que versasse situações cotidianas, conceitos 
científicos, curiosidades e práticas sociais de forma lúdica, prazerosa e interativa.

A série Apolônio \& Azulão surge numa era onde a comunicação tem uma grande importância nos processos que permeiam as relações humanas e sociais, uma era de informação e avanços tecnológicos. Inovadora dentro do conteúdo televisivo voltado ao público infantil, por relacionar diretamente a interatividade gameficada à narrativa audiovisual, a série constitui-se de doze episódios, cada um com quinze minutos de duração. Os personagens manipulados neste teatro de bonecos contracenam com objetos familiares ao universo de crianças de sete a nove anos e, a partir de situações do cotidiano, criam conexões que impulsionam a narrativa envolvendo os personagens.

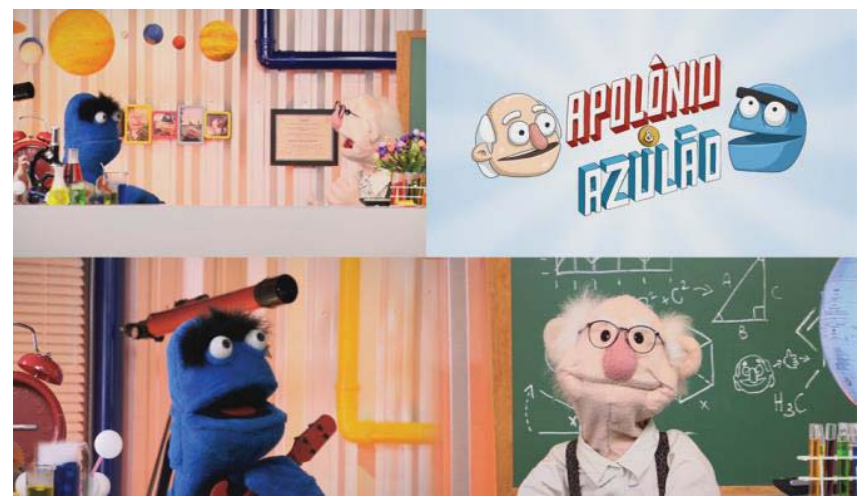

Fig. 01. Personagens e logotipo da série Apolônio \& Azulão

Apolônio é um senhor cientista, cuja aparência demonstra a vivência e a experiência construída ao longo da vida por meio da observação, da atenção e da prática norteada pelos referenciais teóricos - o personagem se envolve em situações que incitam a busca pelo conhecimento por meio da pesquisa, da leitura, da análise. O professor atua nos episódios como investigador do mundo, aberto às observações e curiosidades cotidianas de Azulão. Este por sua vez é um carismático e agitado boneco azul que se aproxima do público infantil pelas suas características físicas, já que sua aparência não se define como humana ou animal. É um misto de boneco, criança e bicho de pelúcia. Suas sobrancelhas largas, peludas e negras, dão destaque aos olhos grandes e inquietos, que representam a curiosidade infantil; a boca representa outra característica infantil marcante nas crianças de sete a nove anos: a fala, usada para se comunicar com as outras pessoas e consigo mesmo. A linguagem empregada no discurso do personagem Azulão é informal, adequada ao discurso usado por crianças e jovens.

Desenvolvida por uma equipe multidisciplinar, a série apresentou como um dos principais desafios aos profissionais envolvidos articular as informações audiovisuais, que se tornaram mais complexas ao relacionar elementos do design de jogos. Roteiristas, produtores, diretores e outros profissionais de produção televisiva atuaram concomitantemente a pedagogos, designers e programadores, envolvidos em todo o processo de concepção e estruturação da atração de modo a efetivar narrativas que mantenham o interesse das crianças.

O desenvolvimento da série parte da premissa de que um programa televisivo para ser interativo, deve ser pensado como tal desde o início, ou seja, a ideia não é tornar, mas ser um programa interativo. Ao roteiro clássico utilizado em televisão divido em três colunas áudio, vídeo e técnica - foi acrescida uma quarta coluna que contemplou a interatividade. Assim, o roteiro foi elaborado desde a fase inicial considerando a interatividade atrelada ao conteúdo em momentos específicos do episódio. A escolha dos temas de cada episódio, bem como a forma de abordagem dos conteúdos e a adequação à faixa etária, foram auxiliadas por um profissional da área de pedagogia.

Após a fase de roteirização dos episódios e definição da gameficação dos conteúdos, isto é, determinação de como seriam os jogos propostos na interatividade, feita em conjunto com os designers e programadores, os episódios foram gravados considerando os momentos de interatividade. Simultaneamente, inciou-se o desenvolvimento das aplicações pelas equipes de design e programação, baseadas na metodologia Agile Development [2], que consiste em gerar subprodutos com objetivo de minimizar a necessidade de prototipagem e correção de falhas após finalizado.

Foram desenvolvidos pequenos projetos e produtos derivados do produto final, assim ao longo do processo, necessidades de alterações e correções de problemas puderam ser detectadas e serem executadas e/ou corrigidas sem a necessidade de alteração de todo o produto. $\mathrm{O}$ desenvolvimento destes subprodutos eliminou a necessidade de longos processos de prototipagem e correções de erros no produto final. Este método foi utilizado em todas as etapas de contrução da série e das interatividades, reforçando o caráter multidisciplinar do produto e necessidade de sinergia entre as equipes.

Cada episódio apresenta dois momentos de interatividade, um Quiz e um jogo, ambos diretamente relacionados ao conteúdo. O Quiz ocorre durante o episódio quando o personagem Azulão aprende uma palavra em inglês e o professor Apolônio o desafia a traduzir esta palavra. Neste momento, Azulão pede a ajuda das crianças de casa que podem escolher, pelo controle remoto, entre as alternativas que são apresentadas na tela. Para os televisores que não têm conversores digitais com Ginga embarcado e que recebem o sinal analógico ou para aqueles que não têm interesse em interagir com o conteúdo, são apresentadas animações e diálogos dos personagens simulando a resposta ao Quiz. Assim mantêm-se o fluxo do programa sem perda de conteúdo para todos os telespectadores, com ou sem interatividade. 


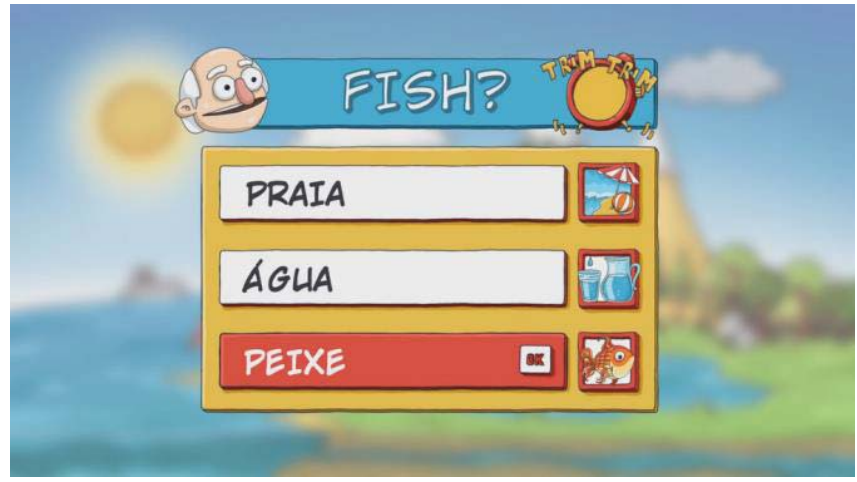

Fig. 02. Quiz interativo desenvolvido em Ginga

O mesmo acontece no segundo momento interativo dos episódios quando ocorrem as gameficações das aplicações. Para os telespectadores que não interagem com o conteúdo via Ginga são apresentadas animações que simulam o personagem Azulão nas mesmas situações e cenários apresentados nos jogos, contando com a ajuda do professor Apolônio e do "público" para resolver os desafios relacionados ao tema.

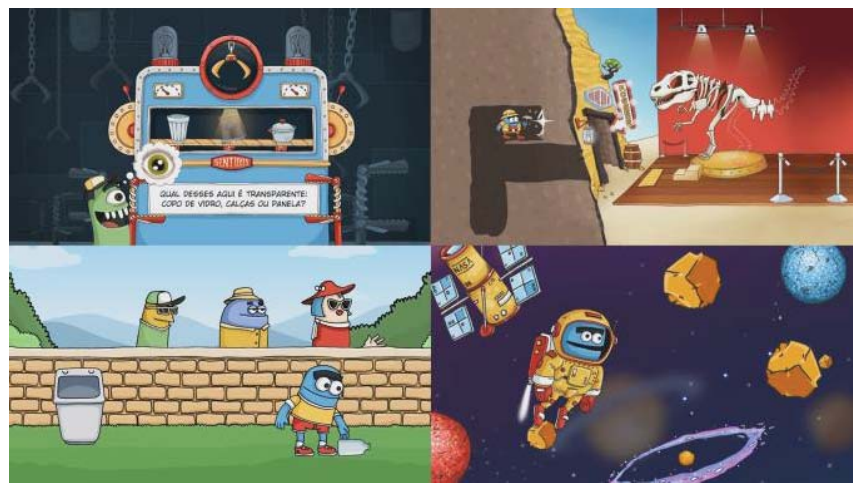

Fig. 03. Interatividade gameficada de quatro episódios da série

A figura 03 ilustra a interatividade de quatro dos doze episódios da série Apolônio e Azulão. Todos os jogos desenvolvidos têm relação direta com a narrativa, por isso a facilidade em substituir a interatividade por animações sem prejuízo de conteúdo ou perda de time entre os diferentes públicos. Como cada episódio apresenta uma interatividade específica ao conteúdo, os desafios e objetivos dos jogos também são específicos ao tema.

Nos exemplos acima, o jogador é solicitado a escolher um objeto para responder uma pergunta, a completar o esqueleto do dinossauro escavando e procurando os ossos, a limpar o parque retirando o lixo jogado pelas pessoas e desviar de planetas, asteróides e satélites no espaço, tudo dentro de um determinado tempo. As tecnologias dos jogos digitais proporcionam uma experiência estética visual e espacial muito rica e, com isso, são capazes de seduzir os jogadores e atraílos para dentro de mundos fictícios que despertam sentimentos de aventura e prazer [6]. Todos os doze jogos desenvolvidos para a série foram formados por ações e decisões limitadas por um conjunto de regras específicas que reverteram a uma condição final numa atividade lúdica e educativa. Foram incorporados à narrativa audiovisual elementos de games como sistema de feedback, sistema de recompensa, conflito, cooperação, competição, objetivos e regras, níveis, tentativa e erro, diversão e interação.

\section{DESENVOLVIMENTO DOS GAMES}

A TV Unesp foi uma das dez emissoras de TV brasileiras que foram contempladas com um laboratório de produção de aplicativos interativos para televisão digital no âmbito do projeto governamental "GINGA BR Labs". Os equipamentos fruto deste projeto permitem a transmissão de alcance curto de um sinal no SBTVD-T a uma distância suficiente para alcançar os dois televisores (um da marca Sony, outro da marca Philco, ambos com Ginga embarcado) que também fazem parte do laboratório; isso possibilita uma simulação acurada de aspectos difíceis de se representar utilizando softwares de emulação do Ginga em computador, tais como velocidade de carregamento de aplicações e o comportamento próprio de cada televisão. Esta possibilidade de se testar os aplicativos diretamente nos televisores foi fundamental para o bom andamento do projeto "Apolônio e Azulão", cuja característica principal é a fusão entre a narrativa audiovisual e as possibilidades interativas de modo indivisível.

Os aplicativos desenvolvidos para a série Apolônio e Azulão foram programados em Ginga, mais especificamente em NCL/LUA. Como as ferramentas específicas para desenvolvimento em Ginga não atendem aos padrões de programação não-ortodoxos que são necessários para um desempenho otimizado das aplicações (jogos), todas as bibliotecas, gráficos e scripts foram criados pela equipe de programação da TV Unesp, utilizando um software de edição de texto comum, o Notepad++.

O NCL, linguagem de marcação semelhante ao HTML, foi concebido para trabalhar com a apresentação estática de elementos de mídia como imagens, vídeos e texto, em uma alternância de apresentação através de eventos de nós de mídia, os "Conectores Causais" (ou Causal Connectors). É possível reproduzir, parar e pausar mídias, por exemplo, através de âncoras no código. Embora até existam, previstas na norma, algumas transições e animações para estes nós de mídia, nenhum dos recursos nativamente oferecidos pelo NCL são suficientes para a criação de games mais complexos, com movimentação ampla, animações e efeitos especiais. Para isso o NCL prevê o suporte a linguagem de programação LUA, onde há a liberdade de criação de conteúdo dinâmico e possibilidade de, através de equações e técnicas de desenho avançadas utilizando o recurso "Canvas", desenhar gráficos animados na tela. No entanto, embora as técnicas de desenho sejam otimizadas para ocupar o menor espaço possível na memória limitada dos televisores e gastar o mínimo de ciclos do processador do aparelho, existe 
uma preocupação com a performance: o maior desafio ao trabalhar com desenvolvimento de jogos para televisão digital é o desempenho dos equipamentos envolvidos. O parque de televisores capazes de rodar Ginga é muito vasto: há pelo menos uma dezena de marcas, cada uma delas com diversos modelos, de gerações diferentes e, portanto performances distintas. Modelos mais novos de televisores podem contar com processadores potentes, de quatro ou mais núcleos de processamento, porém alguns modelos mais antigos possuem capacidade de processamento menor, versões do Ginga atrasadas e quantidade de memória consideravelmente menos robustas do que aparelhos mais recentes.

Como não há um método seguro de se saber qual televisor o espectador possui em casa, é necessário desenvolver softwares que permitam a maior compatibilidade possível, levando em conta as diferenças entre as implementações do Ginga presentes em cada televisor e também o desempenho nativo de cada aparelho. É, muitas vezes, prudente cortar efeitos ou recursos em prol de uma aplicação compatível. Como exemplo, no game onde o personagem precisa desviar dos meteoros no espaço enquanto "colhe" estrelas com o objetivo de chegar até um ponto determinado, o movimento no espaço é simulado através de um efeito de paralaxe, com movimentação dos elementos em velocidades diferentes, respeitando sua relação a sua profundidade simulada na tela. Televisores mais recentes, como os da Sony, modelo Bravia, fabricados em 2013-2014, dotados de processadores mais robustos e mais memória, conseguem, sem perda aparente de desempenho, desenhar mais de 80 objetos ao mesmo tempo, preenchendo a tela toda e dando uma ilusão muito mais convincente de movimento. Já nos testes com o modelo da Sony da linha fabricada em 2011, mais do que 40 elementos na tela ao mesmo tempo já são prejudiciais a fluidez do game. Antes do início do jogo é feito um breve teste oculto de desempenho, onde os efeitos são ajustados de acordo com a capacidade do aparelho de reprodução. Quando a limitação de recursos com base do desempenho da plataforma é possível é bastante proveitoso implementá-las para uma boa experiência de jogo para todos os espectadores.

Contudo, ainda existe o problema da limitação geral da plataforma. Jogos são peças de programação que comumente exigem muito da máquina em que estão rodando. Muitas vezes é necessário transmitir a ilusão de movimento, com animações complexas, contagem de score, várias coisas acontecendo ao mesmo tempo na tela. O maior desafio presente neste projeto é conseguir que os jogos rodem em uma taxa de frames por segundo aceitável, de preferência podendo desenhar na tela 30 vezes por segundo ou até mais rápido, para que a ilusão de movimento dada pelos desenhos alternados seja satisfatória.

Ficou claro para a equipe de desenvolvimento, durante os trabalhos, que somente o NCL e seus recursos não seriam suficientes para criação de jogos mais elaborados. O suporte do Ginga/ $\mathrm{NCL}$ a linguagem declarativa LUA, e consequentemente as suas primitivas de desenho possibilitavam a liberdade de posicionamento e ação necessárias para a tarefa. No entanto, devido aos fatores limitantes de desempenho já citados, foram necessárias a criação de várias rotinas de otimização e reaproveitamento de imagens e códigos, algumas delas dirigidas para cada aparelho e suas peculiaridades, para que o desempenho das aplicações fosse satisfatório até nos televisores com potência de processador menores.

Dentre várias otimizações, duas merecem destaque: A restrição da área de desenho e a captura de teclas fora da rotina principal do jogo.

$A$ restrição das áreas de desenho da tela através de algoritmos de seleção. É possível, via as funções "attrClip" e "attrCrop", disponíveis no LUA, desenhar imagens apenas em uma porção pequena da tela. Por padrão, qualquer rotina de desenho "cola" uma imagem no quadro principal usando todos os pixels disponíveis na tela - 1280 pixels de largura por 720 pixels de altura já que, por padrão, o tamanho do Canvas de desenho no Ginga difere da resolução padrão 1080i). Utilizando das funções de limitação, ao invés do processamento do quadro todo, restringe-se o número de pixels do redesenho ao mínimo realmente necessário. Como devido ao paradigma imediato de desenho do Canvas tudo que for inserido nele é imediatamente "colado" no mesmo, apagar e redesenhar somente um pequeno pedaço do quadro aumenta a performance a níveis consideráveis. Normalmente seria de se esperar que as próprias rotinas de desenho dentro do firmware do Ginga se encarregassem de otimizar estes redesenhos, mas o aumento do desempenho notado faz supor que esta otimização varia muito de plataforma para plataforma.

Outro ponto importante para um desempenho fluído do game é captura dos eventos das teclas do controle remoto em rotina paralela ao núcleo (loop) do jogo. Para desenhar o jogo na tela de forma a dar uma ilusão convincente de fluidez de movimento são necessários, 20 re-desenhos por segundo, com um ideal de 30, pelo menos. Para este projeto, o método escolhido foi a criação de uma função, que roda em um loop eterno, em um período pré-definido de tempo entre 20 e 30 vezes por segundo, que se encarrega de desenhar os gráficos da aplicação. Como os eventos de tecla do Ginga são assíncronos, incluir a previsão destes movimentos dentro da rotina de desenho é um desafio. A solução escolhida foi se aproveitar das "corrotinas", técnica de simulação de "multithread" (processamento de múltiplas tarefas ao mesmo tempo) que permite que - LUA, que é mono tarefa por natureza, processando todos os códigos em sequência, ao mesmo tempo em que desenha algo na tela, respondesse as teclas do controle remoto e tomasse as ações necessárias.

Além das técnicas de programação, também é importante citar as restrições e otimizações necessárias na produção das artes usadas nos jogos. Limitações na memória dos televisores e limites no tamanho do 
aplicativo tornaram também obrigatórias regras a serem seguidas durante o desenho das imagens dos jogos também desenvolvidas pela TV Unesp. Todas as ilustrações usam largas áreas de cores chapadas, com uma paleta cromática reduzida e várias ilustrações foram feitas pensando em clonagem, ampliação via algoritmo e até reaproveitamento dentro do desenvolvimento dos jogos.

Todas estas customizações, sejam de arte ou programação, permitiram que todos os aplicativos funcionassem satisfatoriamente em todos os televisores testados, dentro e fora do ambiente da TV Unesp, com poucas diferenças. Como esperado, televisores mais novos conseguem desempenho e fluidez melhores do que os televisores antigos, porém a jogabilidade e acuidade gráfica dos programas interativos é mantida em uma alta gama de dispositivos.

\section{CONSIDERAÇÕES FINAIS}

Este trabalho apresenta os avanços na maneira de encarar a utilização da interatividade em televisão digital. Ao aliar jogos digitais à narrativa televisiva, a série Apolônio e Azulão oferece possibilidades de explorar as potencialidades da interatividade no processo de assimilação do conteúdo por meio de jogos digitais educativos desenvolvidos em Ginga. A seção anterior demonstra o processo de desenvolvimento das aplicações que abarcou uma série de otimizações por conta das restrições de hardware e softwares encontrados nos diversos tipos de televisores, mas, sobretudo, evidencia que é possível tornar a interatividade mais atrativa graficamente e combinar elementos do design de jogos à interatividade televisiva.

Toda tentativa de explorar novas formas de utilização da interatividade em televisão digital cria expectativas relacionadas aos seus resultados, principalmente quando se trata de processos educativos para o público infantil. O processo de gameficação do conteúdo audiovisual representa uma inovação que pode despertar o interesse de crianças para uso da interatividade na televisão digital. Por apresentar um ambiente lúdico atraente e interativo, os jogos capturam a atenção das crianças ao oferecer desafios que tornam as práticas educacionais informais motivadoras, dinâmicas e ativas.

Com lançamento previsto para outubro deste ano, a série Apolônio e Azulão passará ainda por testes de recepção de conteúdo e usabilidade dos aplicativos, a fim de garantir a adequação dos temas às gameficações, além de verificar os estímulos das capacidades sensoriais e cognitivas dos usuários.

\section{REFERÊNCIAS}

[1] A. G. D. Corrêa, A. A. G. Martinazzo, L. C. Biazon, M. Archanjo, V. Venâncio, I. K. Ficheman, R. D. Lopes; "Jogos Educacionais para TV Digital Interativa", Revista Trilha Digital, V.1 № 1, Pg. 38 50, São Paulo, Brasil, 2013.
[2] F. R. Geloneze; "Modelo de Produção de Aplicação Interativa para Sistema Brasileiro de Televisão Digital Terrestre em Ginga", Anais do XXXIII Congresso Brasileiro de Ciências da Comunicação, Caxias do Sul, Brasil, setembro de 2010.

[3] G. J. Moreira, C. Ellwanger; "Gameficação e Padrões de Interface para Dispositivos Móveis no Estabelecimento do Processo de Ensino e de Aprendizagem", Anais do $3^{\circ}$ SENID, Passo Fundo, Brasil, abril de 2014.

[4] IBGE, Instituto Brasileiro de Geografia e Estatística; "PNAD - Pesquisa Nacional por Amostra de Domicílios 2013", Brasil, setembro de 2014.

[5] M. L. Fardo; "A Gamificação Aplicada em Ambientes de Aprendizagem", Revista Novas Tecnologias na Educação, V.11 №12, Porto Alegre, Brasil, julho de 2013.

[6] R. Savi, V. R. Ulbricht; "Jogos Digitais Educacionais: benefícios e desafios", Revista Novas Tecnologias na Educação, V.6 № 2, Porto Alegre, Brasil, dezembro de 2008.

\footnotetext{
Cite this article:

Silveira de Azevedo, L., Cardoso, F.;2015. Jogos Educativos em TVDi: A gameficação do Ginga. SET EXPO PROCEEDINGS. ISSN Print: 2447-0481.ISSN Online: 2447-049X. v.1. doi: 10.18580/setep.2015.1.15 Web-link: http://dx.doi.org/10.18580/setep.2015.1.15
} 